\title{
Fuzzy Control System Design for Wheel Slip Prevention and Tracking of Desired Speed Profile in Electric Trains
}

\author{
Bijan Moaveni ${ }^{1}$, Fatemeh Rashidi Fathabadi ${ }^{2}$, Ali Molavi ${ }^{3}$ \\ ${ }^{1}$ Center of excellence for Modelling and Control of Complex Systems, Faculty of Electrical \\ Engineering, K. N. Toosi University of Technology, Tehran, Iran. \\ Email: b.moaveni@kntu.ac.ir \\ ${ }^{2}$ PhD student, Department of Electrical and Computer Engineering, Western Michigan \\ University, Michigan, United States of America. \\ Email: Fatemeh.rashidifathabadi@wmich.edu \\ ${ }^{3}$ PhD candidate, Institut de Robòtica i Informàtica Industrial (CSIC-UPC), Polytechnical \\ University of Catalonia (UPC), Barcelona, Spain. \\ Email: ali.molavi@upc.edu
}

\begin{abstract}
This study proposes an anti-slip control system for electric trains based on the fuzzy logic theory, which prevents the wheels from slipping during the acceleration and simultaneously tracks the desired speed profile. To improve the control performance, the train longitudinal velocity and the slip ratio are estimated. By using a Field Oriented Control (FOC), the angular speed of the traction motor is controlled. The fuzzy control system determines the desired angular speed of the traction motor as the reference input of FOC to obtain the desired slip ratio and track the desired speed profile. Simulation results show the effectiveness of the control system in various wheel-rail surface conditions based on the real parameters of ER24PC locomotive.
\end{abstract}

Keywords: Slip controller, Electric train, Longitudinal velocity, Fuzzy Control, Field oriented control. 


\section{NOMENCLATURE}

$B_{m} \quad$ Motor friction coefficient

$B_{w} \quad$ Wheel friction coefficient

$C_{a} \quad$ Air resistance coefficient

$e_{v} \quad$ Train velocity error

$V_{s} \quad$ Slip velocity

$e_{\lambda} \quad$ Slip ratio error

$F \quad$ Friction force

$f_{s} \quad$ Nominal frequency

$g \quad$ Gravitational acceleration

$i_{q s} \quad$ q- axis stator current

$i_{d s} \quad \mathrm{~d}$ - axis stator current

$i_{q r} \quad \mathrm{q}$ - axis rotor current referred to stator

$i_{0 s} \quad$ Base stator current

$i_{0 r} \quad$ Base rotor current referred to stator

$i_{d r} \quad \mathrm{~d}$ - axis rotor current referred to stator

$J_{m} \quad$ Moment inertia of the rotor

$J_{w} \quad$ Moment inertia of a wheel-set

$k \quad$ Sample number

$m \quad$ Train mass

$p \quad$ Numbers of poles of traction motor

$R \quad$ Gear ratio

$r_{m} \quad$ Rotor radius

$r_{w} \quad$ Wheel radius

$r_{s} \quad$ Stator resistance

$r_{r} \quad$ Rotor resistance referred to stator

$T_{s} \quad$ Sampling time

$v \quad$ Train longitudinal velocity

$v_{d} \quad$ Train desired velocity

$\hat{v} \quad$ Train estimated longitudinal velocity

$V_{q s} \quad$ q- axis stator voltage

$V_{d r} \quad$ d-axis rotor voltage referred to stator

$V_{0 s} \quad$ Base stator voltage

$V_{0 r} \quad$ Base rotor voltage referred to stator

$V_{d s} \quad$ d- axis stator voltage

$T_{r} \quad$ Time constant
$V_{q r} \quad$ q- axis Rotor voltage referred to stator

$X_{l r} \quad$ Rotor leakage reactance per phase referred to stator

$X_{l s} \quad$ Stator leakage reactance per phase

$X_{M} \quad$ Magnetizing reactance per phase

$\mu \quad$ Adhesion coefficient

$\hat{\mu} \quad$ Estimated adhesion coefficient

$\tau_{e} \quad$ Electrical torque

$\tau_{l} \quad$ Load torque

$\tau_{w} \quad$ Wheel torque

$\tau_{f} \quad$ Adhesion torque

$\hat{\tau}_{f} \quad$ Estimated adhesion torque

$\hat{\tau}_{e} \quad$ Estimated Electrical torque

$\tau_{e} \quad$ Electrical torque $B_{m}$

$\psi_{q s} \quad$ q-axis stator flux linkage per second

$\psi_{d s} \quad$ d- axis stator flux linkage per second

$\psi_{m q} \quad \mathrm{q}$ - axis magnetizing flux linkage

$\psi_{m d} \quad \mathrm{~d}$ - axis magnetizing flux linkage

$\psi_{0 s} \quad$ Stator base flux linkage per second

$\psi_{0 r} \quad$ Rotor base flux linkage per second referred to stator

$\psi_{d r} \quad$ d- axis rotor flux linkage per second referred to stator

$\psi_{q r} \quad$ q- axis rotor flux linkage per second referred to stator

$\hat{\psi}_{q s} \quad$ Estimated value of $\psi_{q s}$

$\hat{\psi}_{d s} \quad$ Estimated value of $\psi_{d s}$

$\omega_{w} \quad$ Wheel angular speed

$\omega_{m} \quad$ Motor angular speed

$\omega_{b} \quad$ Base electrical angular speed

$\omega$ The angular velocity of arbitrary reference frame

$\omega_{r} \quad$ Electrical angular speed of rotor

$\hat{\lambda} \quad$ Estimated slip ratio

$\lambda \quad$ Slip ratio

$\lambda_{d} \quad$ Desired slip ratio

$L_{m} \quad$ Mutual inductance

$L_{r} \quad$ Inductances for the rotor

$R_{r} \quad$ Rotor resistance

$\theta_{r} \quad$ Electrical rotor angle computation 


\section{Introduction}

Rail transit is a safe, reliable, and energy-efficient form of transportation [1]. By increasing the number of passengers, the demands to reduce the headway and to increase the trains speed have been increased. The first step to obtaining these goals is designing an optimal speed profile with maximum acceleration, maximum allowed speed in the track, and maximum deceleration in the braking phase. The second step is developing and implementing the appropriate control systems in traction and braking systems to track the desired speed profile in the acceleration, cruising, and braking modes. It is evident that tracking the desired speed profile and obtaining the maximum acceleration without controlling the adhesion force between the wheel and rail is not possible [2], [3]. Automatic train operation (ATO) system generally consists of two main parts, (i) generating the optimal speed profile and (ii) tracking strategy to track the optimal speed profile [4], [5], [6].

In railway, tracking the desired speed profile without considering the wheel slip is not practical, since the friction coefficient has a low value. In the acceleration and braking modes, tracking the desired speed profile must be considered along with wheel slip control [7]. To have a perfect traction system operation, both achieving the appropriate value of slip ratio and tracking the desired speed profile must be met [4], [7], [9].

The slip velocity and slip ratio in the acceleration mode are defined as (1) and (2), respectively [9], [10], [11], [12], [13], [14], [15]. In railway vehicles, increasing the slip ratio decreases the friction between the rail and the wheel, where results in less tractive effort, where it is not desirable [11], [16]. Consequently, maintaining the slip ratio in the optimal interval improves the tractive effort and reduces both energy consumption and maintenance costs.

$$
\begin{aligned}
& V_{s}=r_{w} \omega_{w}-v \\
& \lambda=\frac{r_{w} \omega_{w}-v}{v}=\frac{V_{s}}{v}
\end{aligned}
$$

There are various types of slip control systems in the literature [17], [18], [19] and [20]. These control strategies can be categorized in the following classes:

- Fuzzy logic and Intelligent Control Systems

- Nonlinear Control systems

- Control strategies based on the slip estimation

\subsection{Fuzzy Control and Intelligent Systems}

In [5], a multi-modal fuzzy PID (MM-FPID) control algorithm was presented to track the desired speed profile for freight trains. The fuzzy system adjusted the parameters of the PID controller. Based on the idea of the self-learning characteristic of neural networks (NNs), a controller consists of NNs and MM-FPID has been proposed. The simulation results showed the success of the control strategy for tracking the desired speed profile in the presence of timedelay [5]. A fuzzy slip controller was proposed in [21]. The control structure consists of two loops. The outer loop was for speed control and consists of a PI controller, and the inner loop 
was for slip control and consists of a fuzzy logic controller, which produces the optimal set point. The drawback of [21] is that the dynamic of traction motors has not been considered in the model. Kwon et al. [22] introduced a fuzzy adhesion control system in addition to a disturbance observer to estimate the adhesion force coefficient. The introduced approach has a complex fuzzy controller, and clearly, there are certain limitations in practical application. Spiryagin and Lee [23] proposed an adhesion control system to control the slip ratio based on an observer and fuzzy systems, which determines the maximum tractive torque. In this control system, the friction coefficient was detected using a noise spectrum analysis. Frylmark and Johnsson [24] have presented two slip control systems to prevent low friction between the rail and wheel. These methods were introduced based on an adaptive algorithm and fuzzy logic control. The control structures have two loops. An outer loop is for speed control, and an inner loop is for slip control. Time differential of slip and time differential of adhesion force were the input variables, and the compensation of torque was the output of the inner loop. Reference torque was the output of the outer loop. These two outputs integrated and generated the desired torque command. Frylmark and Johnsson have not considered an accurate model of traction motors in the train model [24].

\subsection{Nonlinear Control Methods}

In [25], an Adaptive Fuzzy Sliding-Mode Control was employed to control the slip ratio and regulate it to the desired value in the braking mode. The second Lyapunov theorem was used to prove the closed-loop asymptotic stability, while the model of traction motor has not been considered in the train dynamic. The multi-body dynamics method was used for simulating the longitudinal dynamics of ER24PC locomotive. Lu et al. [26] introduced a robust adaptive re-adhesion control scheme based on the Lyapunov theorem for high-speed trains. Uyulan et al. [27] presented a modified super-twisting sliding mode and robust adaptive to control the slip in acceleration and braking modes. Lu et al. [28] presented a robust adaptive cooperative control to control the slip velocity in high-speed trains. [29] and [30] introduced an integral sliding mode control to obtain the optimal adhesion. The advantage of the method is its robustness in dealing with model uncertainty and disturbances, while the dynamic of the traction motors has not been considered in the model.

\subsection{Control strategies based on the slip estimation}

Pichlik and Zdenek [31] proposed a slip control method based on the Unscented Kalman Filter (UKF) to estimate the adhesion condition. This method improved the weakness of the classical methods by estimating the relative adhesion force as the controller input. A PI controller has been used to avoid the high value of wheel slip velocity. Zhao and Liang [32] presented a slip detection and re-adhesion control methodology in which an extended Kalman filter was used to estimate creepage, creep force, and traction coefficients. The proposed readhesion control method was applied to regulate the electric torque of the AC traction motor. Sadr and Khaburi [33] proposed perturbation and observation-based control to obtain maximum adhesion force in traction mode. Their control strategy was simulated and 
implemented in a test rig. Wen et al. [34] proposed distributed Model Predictive Control (MPC) as a re-adhesion control system in four axes of the electric locomotive.

Mei et al. [35] suggested a mechatronic approach for the detection of wheel slip/slide and an anti-slip control in railway traction systems. In their method, the slip ratio was estimated by an observer based on wheel-set torsional vibration. Depending on the magnitude of the estimated torsional torque, a conventional PI controller was tuned to reduce the actual level of torque. Kadowaki and Ohishi [36] introduced anti-slip/anti-slide re-adhesion control using a disturbance observer and sensor-less vector control. The effectiveness of the method was analyzed and validated by applying it to an actual electric multi-unit series 205-5000. Kawamura et al. [37] developed an adhesion test equipment to measure the tractive force and proposed a tractive force control in the slip region. Their control strategy was based on the time derivative of slip ratio and tractive force. Achour and Debbou [38] introduced an average differential control as an anti-slip strategy in dealing with dual-induction motors that use as the railway traction system. Cooperative control was used to generate the voltage references introduced in the PWM block to reduce the number of control units. The proposed drive control cancels the difference between motor torques if an unbalanced load in the traction system caused by changes in adhesion force originates from slip changes and rail conditions.

Based on the state of the art, some of the researches did not consider the dynamic of the traction motors in the modeling and control strategy. On the other hand, in most of the studies, tracking the desired train speed profile has not been considered with slip prevention, simultaneously. The current study proposes a control strategy based on the fuzzy logic to track the desired speed profile and prevent the wheels from slipping. The proposed control system consists of field-oriented control (FOC) to control the traction motor and a fuzzy logic controller and an estimator to obtain the desired performance. The fuzzy controller generates the deviation of the desired angular speed of the traction motor by considering the desired speed profile and longitudinal velocity of the train. The control system requires the longitudinal velocity value and slip ratio; therefore, an estimator is presented to estimate these variables.

Section 2 provides a brief overview and formulation of induction motor equations and train dynamics. Section 3 introduces the control system strategy consisting of FOC, a fuzzy controller, and an estimator. The simulation results in various scenarios, based on an extended model that contains a vector-controlled induction motor model, wheel-set model, and locomotive motion model are presented in Section 4. Section 5 concludes the paper.

\section{System modeling}

This section presents a model of a train that includes a traction motor (electrical part). Fig. 1 shows the components of the traction system of a train and their relationship to one another. 


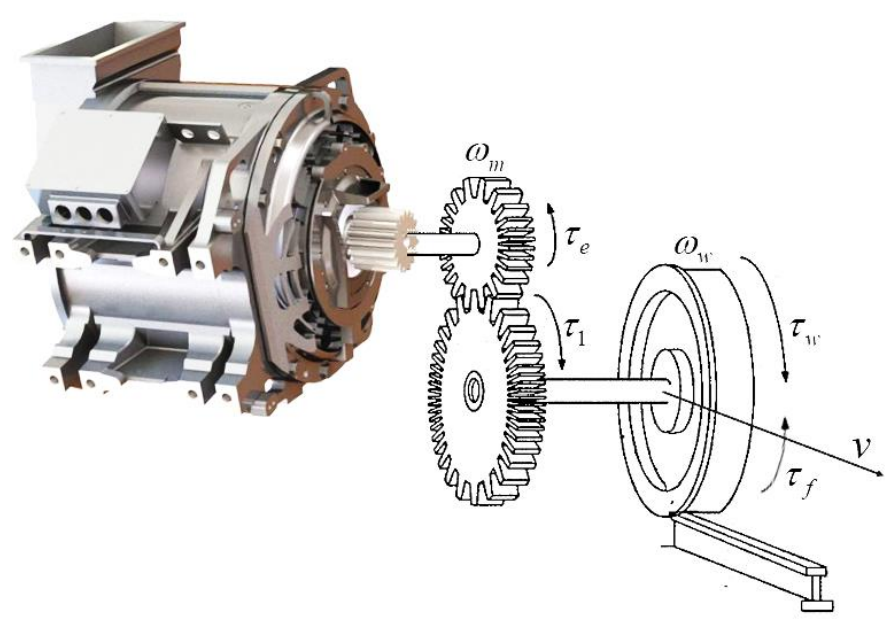

Fig. 1. Traction motor and wheel.

\subsection{Modeling of mechanical parts}

Using Fig. 1, the dynamic equations of the angular speed of the wheel, the longitudinal velocity of the train, adhesion force, and adhesion coefficient can be presented as follows [39]:

$\tau_{e}=B_{m} \omega_{m}-\tau_{1}-J_{m} \dot{\omega}_{m}$

$\frac{\tau_{w}}{\tau_{1}}=\frac{\omega_{m}}{\omega_{w}}=\frac{r_{w}}{r_{m}}=R$

$J_{w} \dot{\omega}_{w}=\tau_{w}-B_{w} \omega_{w}-\tau_{f}$

$m \dot{v}=F-C_{a} v^{2}$

$F=\mu(\lambda) m g$

$\tau_{f}=F r_{w}$

The shared parameter between the longitudinal dynamics of the train in the angular speed of the wheel in Eq. (5) and Eq. (6) is the adhesion coefficient, $\mu(\lambda)$. The adhesion coefficient is a nonlinear function of the slip ratio. As it has been shown in Fig. 2, the tractive force depends on the slip ratio between the wheel and rail. The Fig. 2 shows that when the slip ratio is within the bounds (0.035-0.05), the maximum adhesion force is created [9], [10]. 


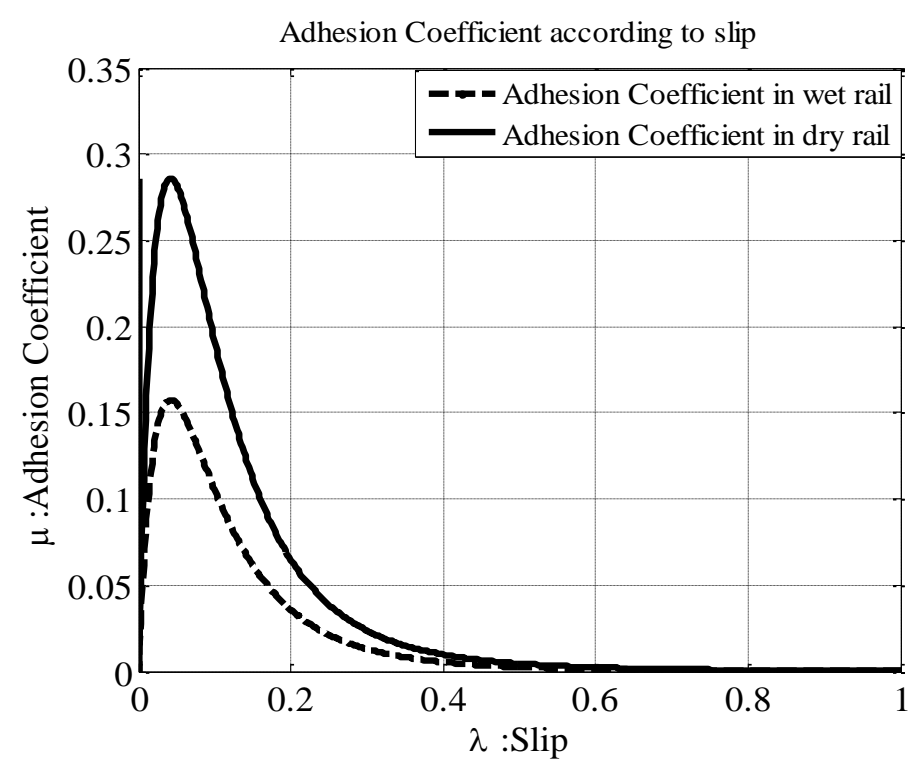

Fig. 2. Adhesion-slip characteristics.

Ishikawa and Song in [9] and [26] introduced an experimental equation (Eq. (9)) to model the adhesion coefficient as a function of slip velocity. The parameters of Eq. (9) have been extracted from the results of real experiments. The parameters for wet/dry wheel-rail surface conditions are shown in Table 1.

$\mu=c \cdot e^{-a V_{s}}-d \cdot e^{-b V_{s}}$

Table 1. The parmaeters of Eq. (9) for two wheel-rail surface conditions.

\begin{tabular}{ccccc}
\hline $\begin{array}{c}\text { Wheel-rail surface } \\
\text { condition }\end{array}$ & $a$ & $b$ & $c$ & $d$ \\
\hline Wet & 0.54 & 1.5 & 0.55 & 0.55 \\
\hline Dry & 0.54 & 1.5 & 1 & 1
\end{tabular}

\subsection{Modeling of electrical parts}

The dynamic equations of an induction motor as the traction motor in the $d-q$ reference frame are presented in Eqs. (10) to (18). All the rotor parameters have been referred to the stator [40], [41].

$\dot{\psi}_{q s}=\omega_{b}\left[V_{q s}-\frac{\omega}{\omega_{b}} \psi_{d s}+\frac{r_{s}}{X_{l s}}\left(\psi_{m q}-\psi_{q s}\right)\right]$

$\dot{\psi}_{d s}=\omega_{b}\left[V_{d s}+\frac{\omega}{\omega_{b}} \psi_{q s}+\frac{r_{s}}{X_{l s}}\left(\psi_{m d}-\psi_{d s}\right)\right]$

$\dot{\psi}_{0 s}=\omega_{b}\left[V_{0 s}-\frac{r_{s}}{X_{l s}} \psi_{0 s}\right]$ 


$$
\begin{aligned}
& \dot{\psi}_{q r}=\omega_{b}\left[V_{q r}-\left(\frac{\omega-\omega_{r}}{\omega_{b}}\right) \psi_{d r}+\frac{r_{r}}{X_{l r}}\left(\psi_{m q}-\psi_{q r}\right)\right] \\
& \dot{\psi}_{d r}=\omega_{b}\left[V_{d r}-\left(\frac{\omega-\omega_{r}}{\omega_{b}}\right) \psi_{q r}+\frac{r_{r}}{X_{l r}}\left(\psi_{m d}-\psi_{d r}\right)\right] \\
& \dot{\psi}_{0 r}=\omega_{b}\left[V_{0 r}+\frac{r_{r}}{X_{l r}} \psi_{0 r}\right] \\
& X_{a d}=X_{a q}=\left(\frac{1}{X_{M}}+\frac{1}{X_{l s}}+\frac{1}{X_{l r}}\right)^{-1} \\
& \psi_{m d}=X_{a d}\left(\frac{\psi_{d s}}{X_{l s}}+\frac{\psi_{d r}}{X_{l r}}\right) \\
& \psi_{m q}=X_{a q}\left(\frac{\psi_{q s}}{X_{l s}}+\frac{\psi_{q r}}{X_{l r}}\right)
\end{aligned}
$$

The electrical torque of the induction motor is determined as follows:

$\tau_{e}=\frac{3}{2} \frac{P}{2} \frac{1}{\omega_{b}}\left(\psi_{q r} i_{d r}-\psi_{d r} i_{q r}\right)=\frac{3}{2} \frac{P}{2} \frac{1}{\omega_{b}}\left(\psi_{d s} i_{q s}-\psi_{q s} i_{d s}\right)$

where $i_{q s}, i_{d s}, i_{q r}$ and $i_{d r}$ are:

$$
\begin{aligned}
& i_{q s}=\frac{1}{X_{l s}}\left(\psi_{q s}-\psi_{m q}\right) \\
& i_{d s}=\frac{1}{X_{l s}}\left(\psi_{d s}-\psi_{m d}\right) \\
& i_{0 s}=\frac{1}{X_{l s}} \psi_{0 s} \\
& i_{0 r}=\frac{1}{X_{l s}} \psi_{0 r} \\
& i_{q r}=\frac{1}{X_{l r}}\left(\psi_{q r}-\psi_{m q}\right) \\
& i_{d r}=\frac{1}{X_{l r}}\left(\psi_{d r}-\psi_{m d}\right)
\end{aligned}
$$




\section{Control system}

The main objectives of the introduced control system are tracking the desired speed profile and preventing the wheels from slipping at the acceleration mode. In order to obtain these objectives, a control system with block diagram as shown in Fig. 3 is introduced. Please note that the controller and estimator are presented in the discrete time domain with sampling time $T_{s}$. Clearly, in the discrete time domain, the values of the signals at $t=k T_{s}$ are known, where $k$ denotes the sample number. The proposed control system includes three main parts, FOC, Fuzzy controller and estimator. Tasks of each part of the control system are:

- FOC: FOC is used to control the angular speed of the traction motor. Fig. 4 shows the structure of FOC. The hysteresis block of FOC produces a switching signal for the inverter to generate the appropriate three-phase voltages. As shown in Fig. 3 and Fig. 4 , the motor speed is measured and compared with the reference rotational speed. Motor speed feedback is required for the outer-loop speed control and in the fuzzy control algorithm. By defining the reference rotational speed of the wheel based on the desired longitudinal velocity of the train, the desired slip ratio can be obtained [42], [43], and [44].

- Fuzzy controller: Fig. 3 shows that the control system should generate the deviation of reference rotational speed, $\omega_{m}^{*}$, of the traction motor as the reference input of the FOC. The fuzzy controller generates this value to reduce the error between the longitudinal velocity of the train and the desired speed profile and prevent the wheels from slipping.

- Estimator: This part estimates the slip ratio and longitudinal velocity of the train. The error between the desired slip ratio and desired longitudinal velocity and their estimated values are used as the input variables of the fuzzy controller.

\subsection{Fuzzy controller design}

Two main objectives of the introduced control system are:

- Tracking the desired speed profile

- Preventing the wheels from slipping

Fig. 3 shows the block diagram of the proposed control system to obtain the above goals. The system dynamics, including the power electronics, induction motor, and mechanical components, have been modeled separately. As explained above, the control system consists of FOC as the inner control loop to control the rotational speed of the wheel and an anti-slipping fuzzy logic controller for tracking the desired speed profile and preventing the wheels from slipping. Note that the two objectives have only one input variable, and a system with one input variable and two output variables is not functionally controllable. Therefore, the parameters of the PI controller in FOC structure have been tuned in such a way that in different adherence conditions, the rotational speed of the wheel tracks the reference value. 


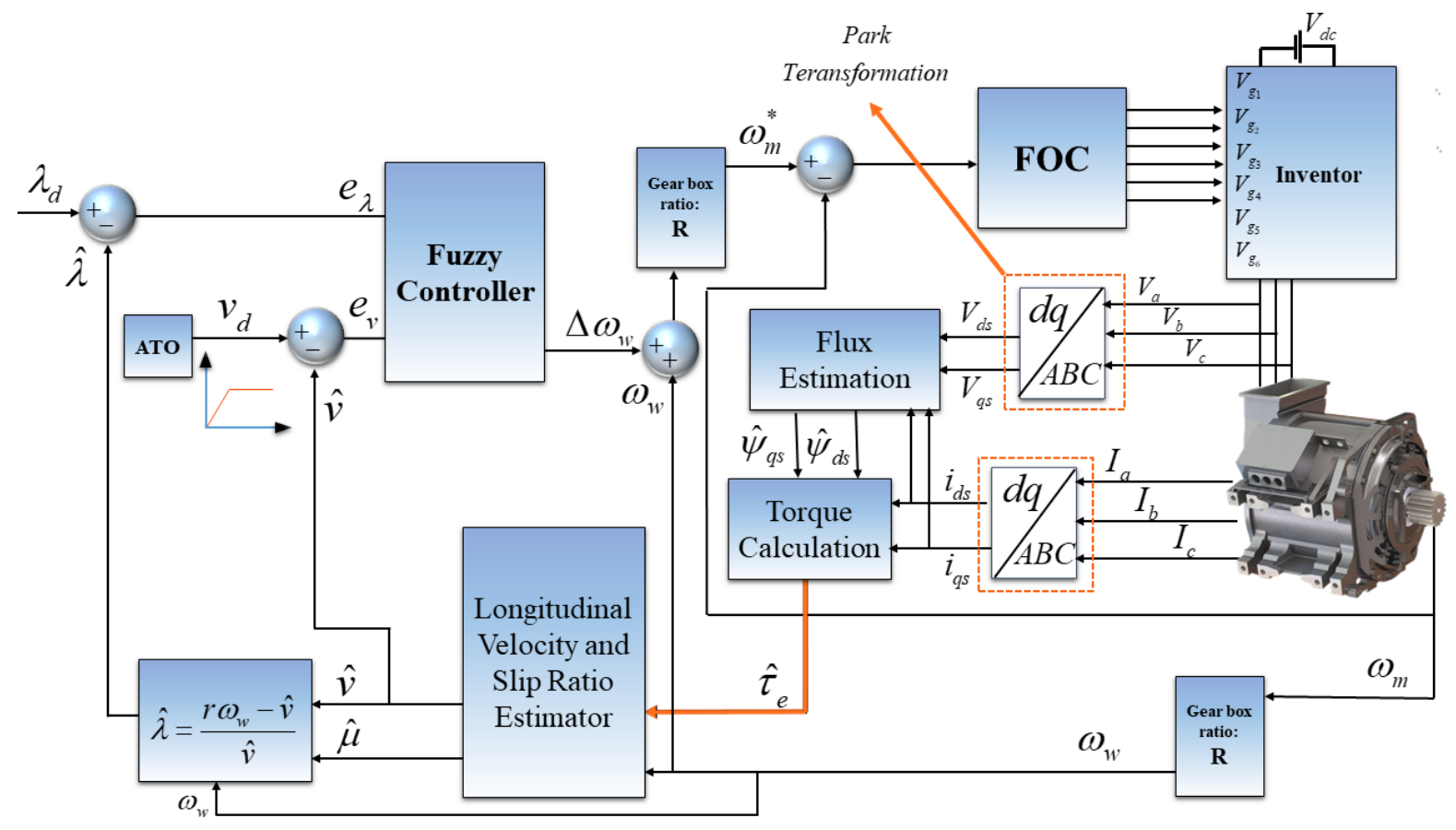

Fig. 3. Block diagram of the introduced control system based on the fuzzy controller.

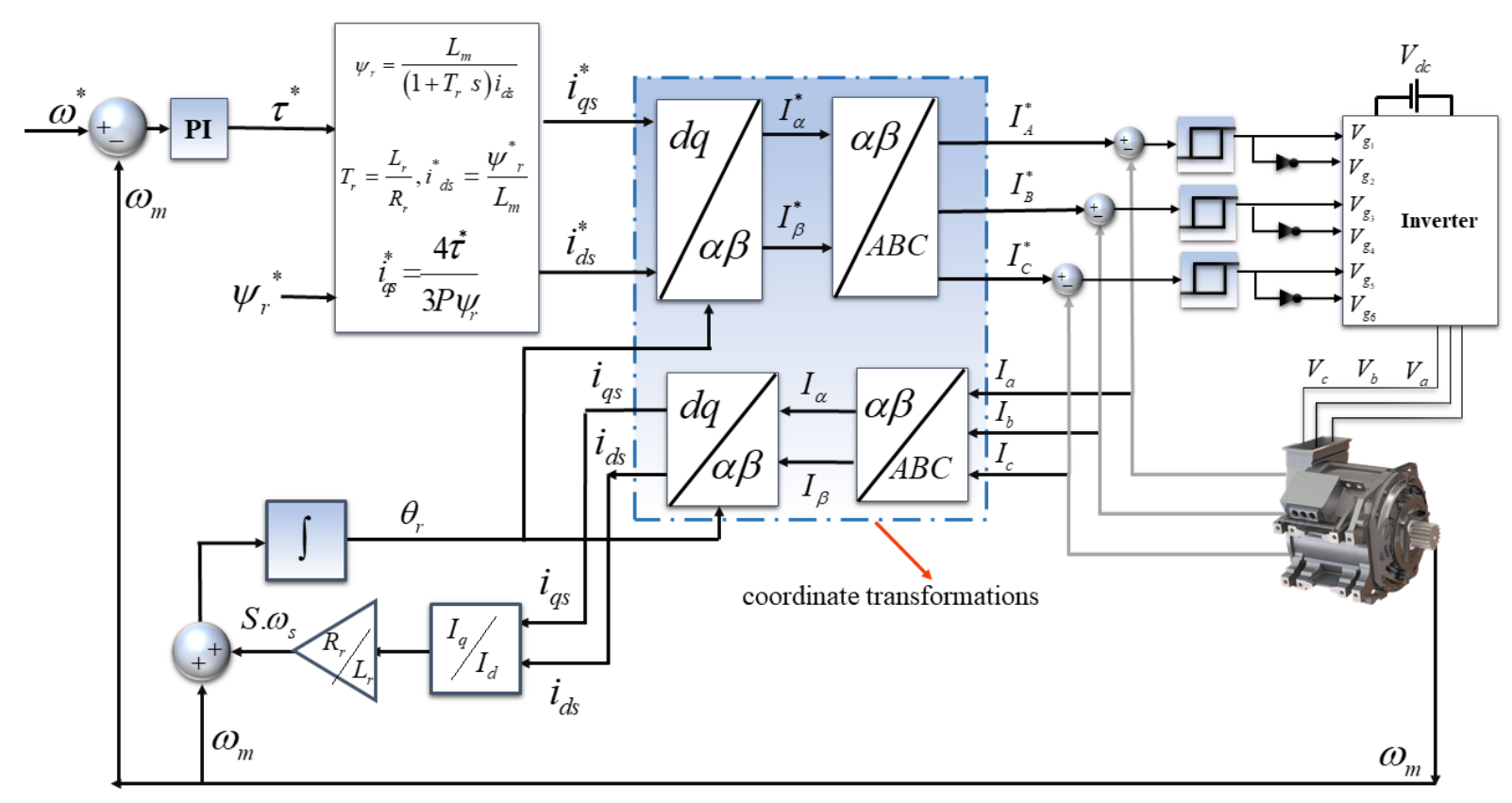

Fig. 4. The field oriented control (FOC) for speed control of the induction motor.

In the proposed control system, FOC controls the rotational speed, and the fuzzy controller should provide its reference input. In the proposed control structure, the fuzzy controller determines the deviation of the desired rotational speed of the motor, which maintains the slip ratio within an appropriate range and tracks the desired speed profile. The proposed fuzzy controller has two inputs: slip ratio error $e_{\lambda}(k)$, and longitudinal velocity error 
$e_{v}(k) . e_{\lambda}(k)$ and $e_{v}(k)$ have been defined in Eq. (26). The output of the fuzzy controller is the deviation of the reference rotational speed of the wheel, $\Delta \omega_{w}$.

$$
\begin{aligned}
& e_{\lambda}(k)=\lambda_{d}(k)-\hat{\lambda}(k) \\
& e_{v}(k)=v_{d}(k)-\hat{v}(k)
\end{aligned}
$$

In this fuzzy system, the triangular membership functions (MFs) have been used for both the inputs and outputs of the system. The fuzzy inference engine is based on the Mamdani method, the center average defuzzifier, and the Singleton fuzzifier. The MFs of input and output variables in the fuzzy system are shown in Fig. 5, and Fig. 6. This fuzzy control system is expressed with two-inputs, one-output, and 25 rules. Using the linguistic variables, the proposed rule based fuzzy system is designed. The linguistic variables: NB, NS, Z, PS, and PB in Table 2 express Negative Big, Negative Small, Zero, Positive Small and Positive Big, respectively. Based on the feasible value of the desired slip ratio and the desired longitudinal velocity in the railway system, the variation bounds of the input and output variables of the fuzzy system are defined as:

$$
\begin{aligned}
& e_{\lambda} \in[-0.05,0.05] \\
& e_{v} \in[-1.5,1.5]^{\mathrm{m} / \mathrm{s}} \\
& \Delta \omega_{w} \in[-3,3]^{\mathrm{rad} / \mathrm{sec}}
\end{aligned}
$$

The fuzzy rules have been developed based on the principle that if both errors have high values, then the high correction value, $\Delta \omega_{w}$, should be used, and in the other cases $\Delta \omega_{w}$ has a smaller value.

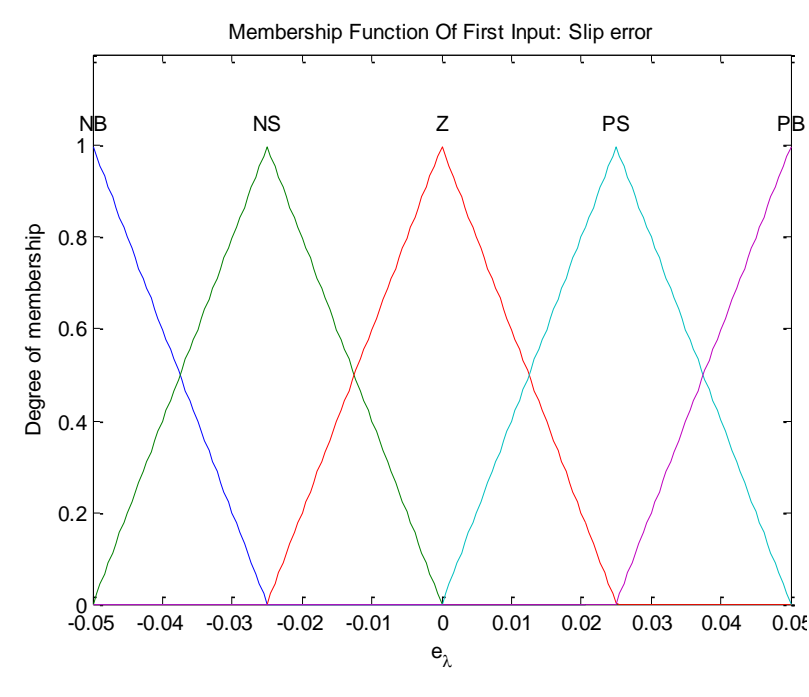

(a)

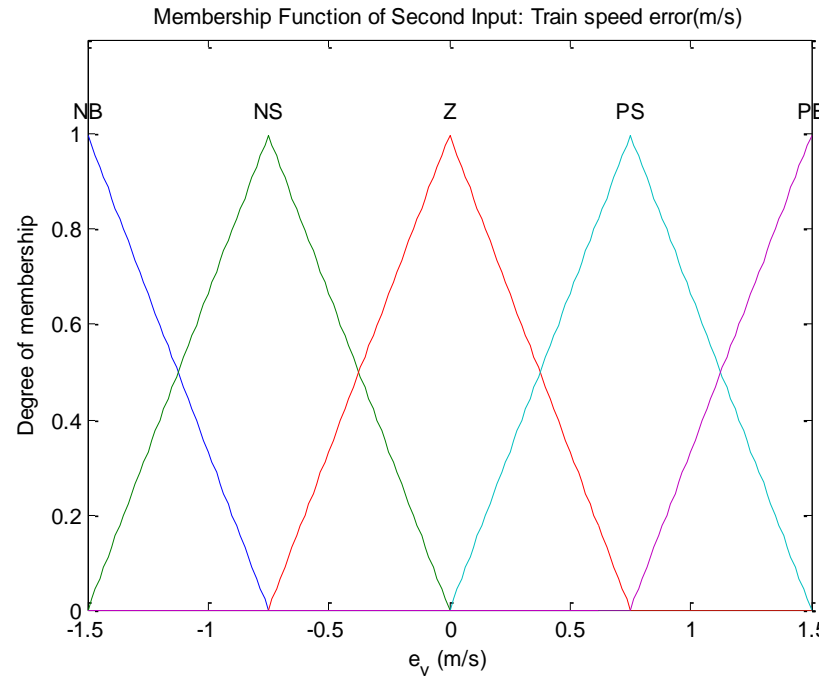

(b)

Fig. 5. Membership functions of the input variables: (a) slip error (b) longitudinal velocity error. 


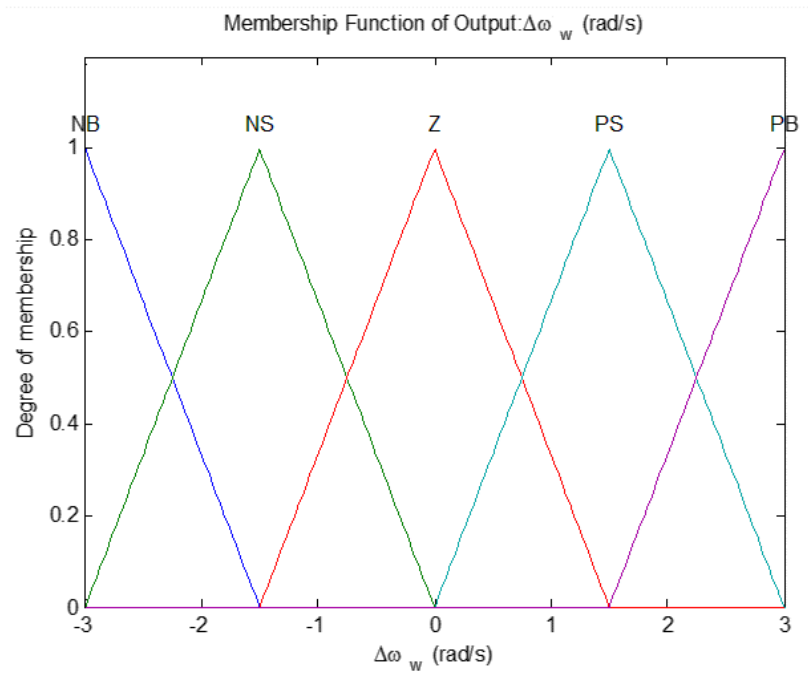

Fig. 6. Membership functions of the output variable: deviation of the reference rotational speed, $\Delta \omega_{w}$

Table 2. Fuzzy logic rules.

\begin{tabular}{|c|c|c|c|c|c|}
\hline$e_{v}$ & NB & NS & Z & PS & PB \\
\hline NB & NB & NB & NS & NS & NS \\
\hline NS & NB & NS & NS & Z & NS \\
\hline Z & NS & NS & Z & Z & PS \\
\hline PS & NS & Z & PS & PS & PB \\
\hline PB & NS & PS & PS & PB & PB \\
\hline
\end{tabular}

\subsection{Estimating the Longitudinal velocity and slip ratio}

The proposed fuzzy controller requires the values of $e_{\lambda}(k)$ and $e_{v}(k)$ in all sample times. For determining the $e_{\lambda}(k)$ and $e_{v}(k), \hat{\lambda}(k)$ and $\hat{v}(k)$ must be estimated. Based on the slip ratio definition in Eq. (2), determining the slip ratio depends on the longitudinal velocity. Since, in real conditions, the condition of the rail and wheel surface changes, and the longitudinal velocity of the train cannot merely be measured [45], [46]. In [42], a sensor-less approach is proposed to estimate the train longitudinal velocity. To estimate the longitudinal velocity, by measuring the three-phase currents and voltages, the stator fluxes and the electrical torque can be estimated using Eqs. (27), (28) and (29), respectively [42], [47]. Eqs. (27)-(29) have been written using Eqs. (9)-(10) and (19)-(21).

$$
\begin{aligned}
& \hat{\psi}_{q s}(k+1)=\hat{\psi}_{q s}(k)+T_{s}\left(\omega_{b}\left(V_{q s}(k)-\frac{\omega(k)}{\omega_{b}} \hat{\psi}_{d s}(k)+r_{s} i_{q s}(k)\right)\right) \\
& \hat{\psi}_{d s}(k+1)=\hat{\psi}_{d s}(k)+T_{s}\left(\omega_{b}\left(V_{d s}(k)+\frac{\omega(k)}{\omega_{b}} \hat{\psi}_{q s}(k)+r_{s} i_{d s}(k)\right)\right) \\
& \hat{\tau}_{e}(k)=\frac{3}{2} \frac{P}{2} \frac{1}{\omega_{b}}\left(\hat{\psi}_{d s}(k) i_{q s}(k)-\hat{\psi}_{q s}(k) i_{d s}(k)\right)
\end{aligned}
$$


By transferring the dynamic equations of the motor in Eq. (3) to the wheel side using the gearbox ratio, and by using the estimated electrical torque in (29), the adhesion torque is estimated as:

$$
\hat{\tau}_{f}(k)=R \hat{\tau}_{e}(k)-\left(B_{w}+B_{m} R^{2}\right) \omega_{w}(k)-\frac{1}{T_{s}}\left(J_{w}+J_{m} R^{2}\right)\left(\omega_{w}(k)-\omega_{w}(k-1)\right)
$$

The adhesion torque in Eq. (30) can be rewritten as (31).

$$
\hat{\tau}_{f}(k)=R \hat{\tau}_{e}(k)-\left(B+\frac{J}{T_{s}}\right) \omega_{w}(k)+\frac{J}{T_{s}} \omega_{w}(k-1)
$$

where $J=J_{w}+J_{m} R^{2}$ and $B=B_{w}+B_{m} R^{2}$. Using Eqs. (7) and (8), the estimated adhesion coefficient is:

$$
\hat{\mu}(k)=\frac{\hat{\tau}_{f}(k)}{m g r_{w}}
$$

Using the wheel dynamics in Eqs. (6)-(8), (31), and (32) the estimated longitudinal velocity can be determined in any samples using (33).

$$
\hat{v}(k)=T_{s} \hat{\mu}(k) g+\left(\hat{v}(k-1)-T_{s} \frac{C_{a}}{m} \hat{v}^{2}(k-1)\right)
$$

Obviously, using Eqs. (2) and (33), the slip ratio can be estimated as (34).

$$
\hat{\lambda}(k)=\frac{r_{w} \omega_{w}(k)-\hat{v}(k)}{\hat{v}(k)}
$$

The main advantage of the presented estimation approach is that the estimator uses the dynamic equations of locomotive and traction motor to estimate the longitudinal velocity and slip ratio. But, in the estimator equations, (27)-(34), it is assumed that parameters $r_{s}, \omega_{b}, R, J$ $, B, C_{a}, r_{w}$ and $m$ have known accurate values. Also, it is assumed that stator currents and voltages, and angular speed of the wheel are accurately measurable. Clearly, any errors in the parameter values result in errors in the $\hat{v}(k)$ and $\hat{\lambda}(k)$, and decrease the control system performance.

\section{Simulation results}

Real parameters of an ER24PC locomotive (Iran-Safir locomotive) have been used to carry out the numerical simulations and to demonstrate the abilities of the proposed strategy to control the longitudinal velocity of the train and prevent the wheels from slipping. The simulations have been done in three cases. Note that, in all cases, the goals are tracking the desired speed profile and preventing the wheels from slipping. Table 3 shows the values of the parameters used in the numerical simulations. These parameters are for an ER24PC locomotive manufactured by MAPNA Locomotive Engineering and Manufacturing Company in cooperation with Siemens. 
Table 3. The simulation parameters

\begin{tabular}{|l|c|l|c|}
\hline \multicolumn{1}{|c|}{ Parameter } & Value & Parameter & Value \\
\hline$m(\mathrm{~kg})$ & 21250 & $r_{r}(\Omega)$ & 5.3743 \\
\hline$J_{m}\left(\mathrm{~kg} \mathrm{~m}^{2}\right)$ & 8.6021 & $r_{s}(\Omega)$ & 3.5395 \\
\hline$J_{w}\left(\mathrm{~kg} \mathrm{~m}^{2}\right)$ & 146.7 & $X_{M}(\Omega)$ & 200.591 \\
\hline$R$ & 4.13 & $X_{l r}(\Omega)$ & 22.3242 \\
\hline$C_{a}\left(s^{2} / \mathrm{m}^{2}\right)$ & 0.5 & $X_{l s}(\Omega)$ & 22.3242 \\
\hline$r_{w}(\mathrm{~m})$ & 0.5 & $f_{s}(\mathrm{~Hz})$ & 36 \\
\hline$B_{m}(\mathrm{~kg} \mathrm{~m} / \mathrm{s})$ & 0.032 & $P$ & 4 \\
\hline$B_{w}(\mathrm{~kg} \mathrm{~m} / \mathrm{s})$ & 0.02 & $T_{s}(\mathrm{sec})$ & $5 \times 10^{-5}$ \\
\hline $\begin{array}{l}\text { Proportional gain } \\
\text { of PI controller }\end{array}$ & 25 & $\begin{array}{l}\text { Integrator gain } \\
\text { of PI controller }\end{array}$ & 10 \\
\hline
\end{tabular}

\subsection{Case 1: Dry condition}

In this case, the wheel-rail surface is dry, and the desired acceleration in the desired speed profile is $1 \mathrm{~m} / \mathrm{s}^{2}$. As shown in Fig. 7 (a) and (b), during acceleration, the estimated slip ratio meets the desired slip bounds [0.035-0.05], and the train tracks the desired speed profile quite well. The torque and three-phase currents of the traction motor are shown in Fig. 8.
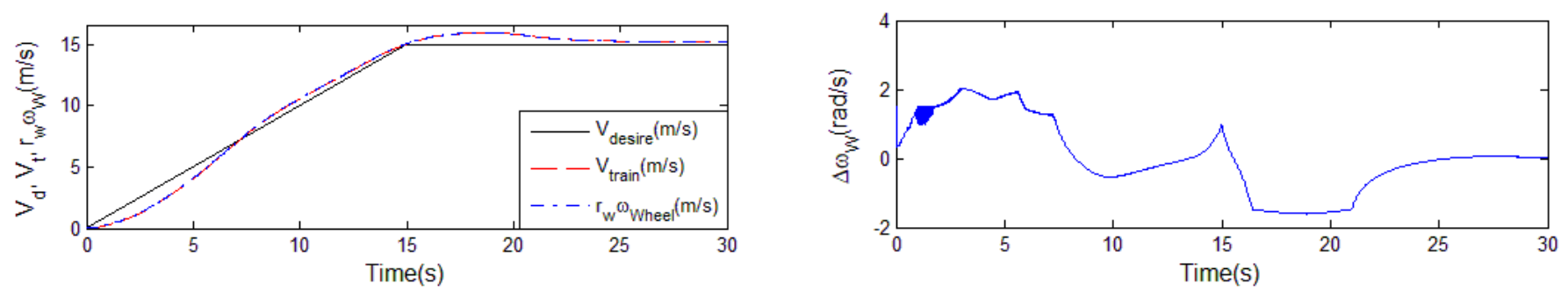

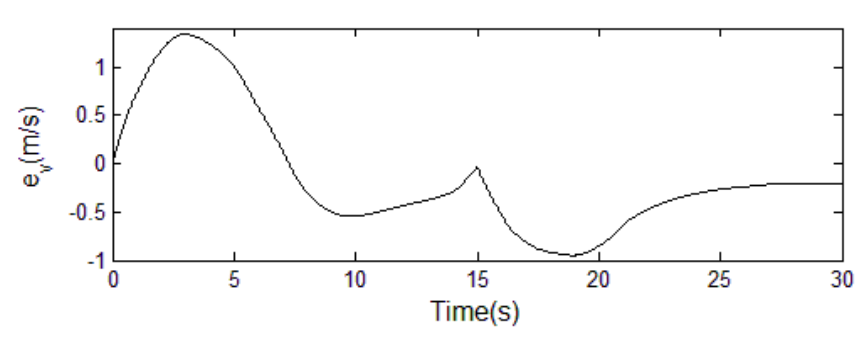

(a)

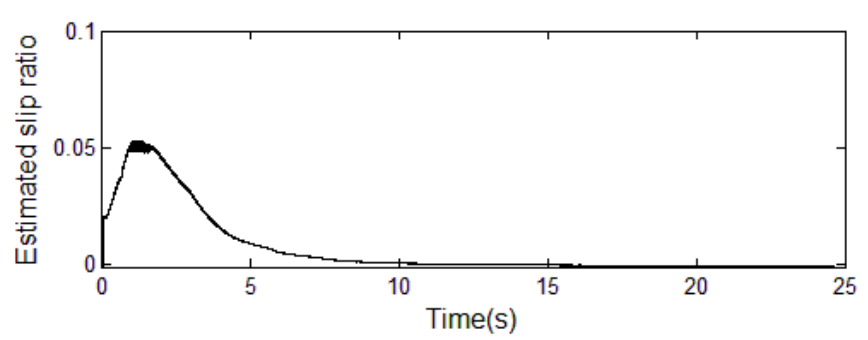

(b)

Fig. 7. Dry condition: (a) tracking the desired speed profile and error between the estimated longitudinal velocity and the desired speed profile; (b) $\Delta \omega_{w}$ and estimated slip ratio. 

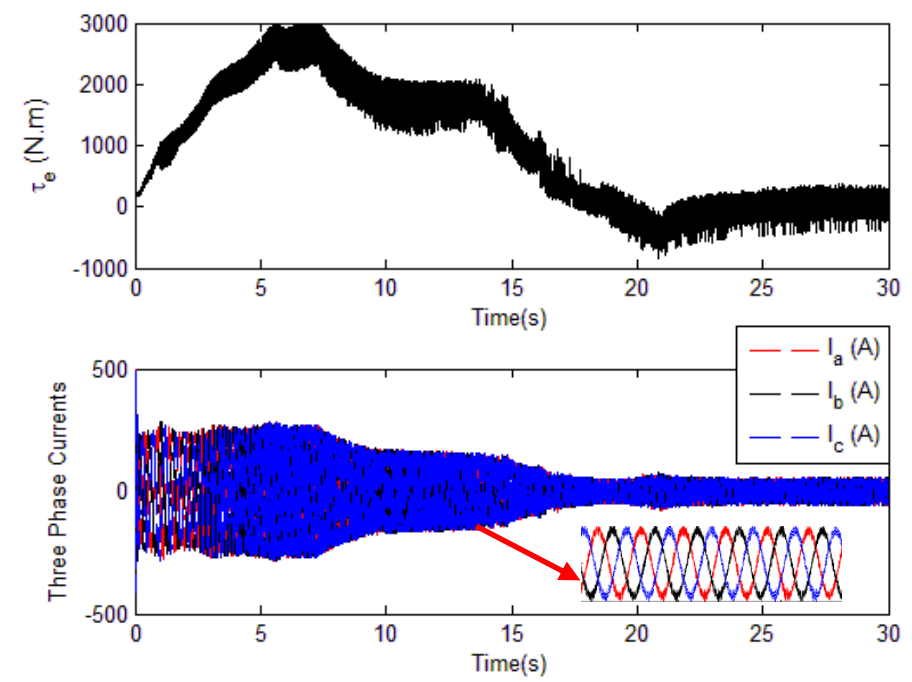

Fig. 8. Dry condition: electric torque and three-phase currents.

To evaluate the proposed fuzzy control system, a Super-twisting Sliding Mode Control (StSMC) [3] has been used. The simulation results for the dry wheel-rail surface have been shown in Fig. 9. The simulation results show that the StSMC could not maintain the slip ratio in the desired bound in the acceleration mode. Furthermore, the longitudinal velocity of the train does not track the desired speed profile in the acceleration mode, but in the cruising mode, tracking the desired speed profile is much better and acceptable.
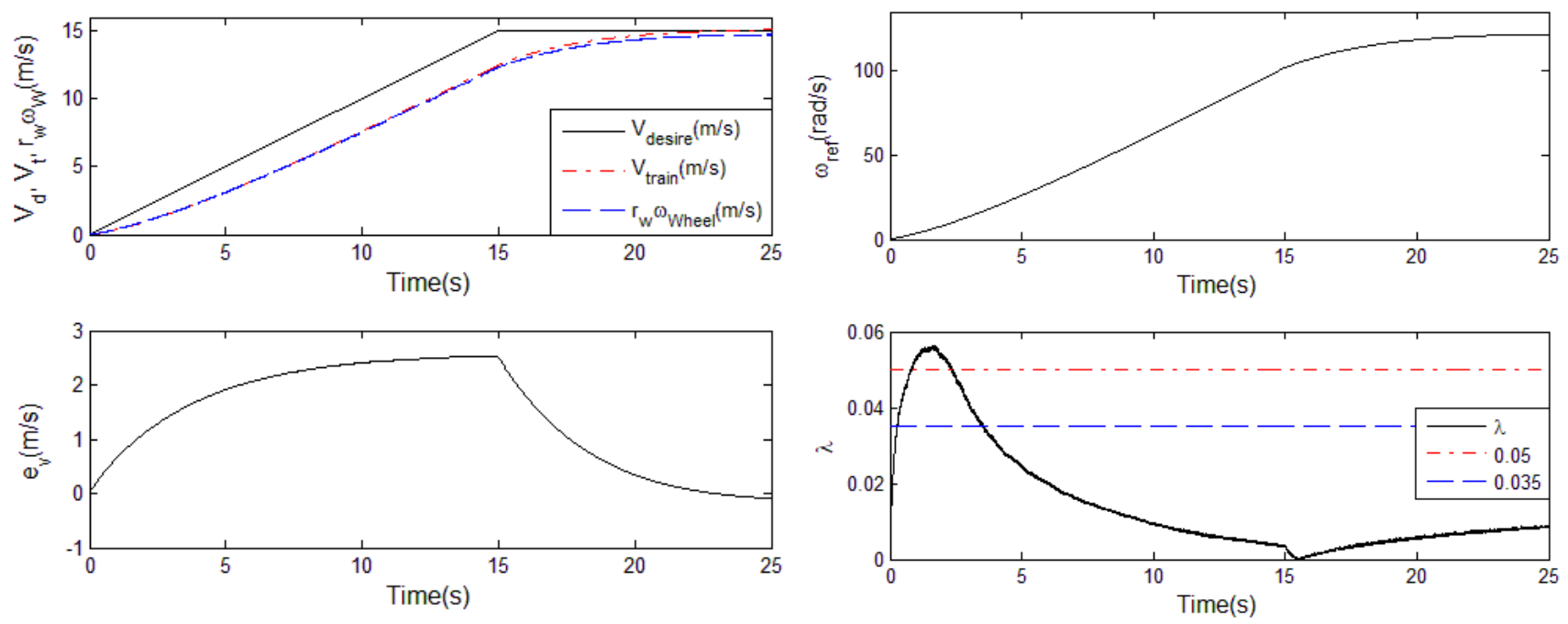

(a)

(b)

Fig. 9. Dry condition: (a) tracking the desired speed profile and error between the longitudinal velocity and the desired speed profile using StSMC; (b) $\omega_{\text {ref }}$ and slip ratio, using StSMC.

\subsection{Case 2: Wet condition}

In this case, the simulation is performed in wet wheel-rail surface conditions. Because of the safety and rail conditions, the acceleration of the desired speed profile is $0.5 \mathrm{~m} / \mathrm{s}^{2}$. At the beginning of the movement, due to the wet surface condition, controlling the slip ratio is more significant. As shown in Fig. 10. (a), and (b) the desired slip ratio has been obtained well, and the longitudinal velocity of the train has tracked the desired speed profile. 

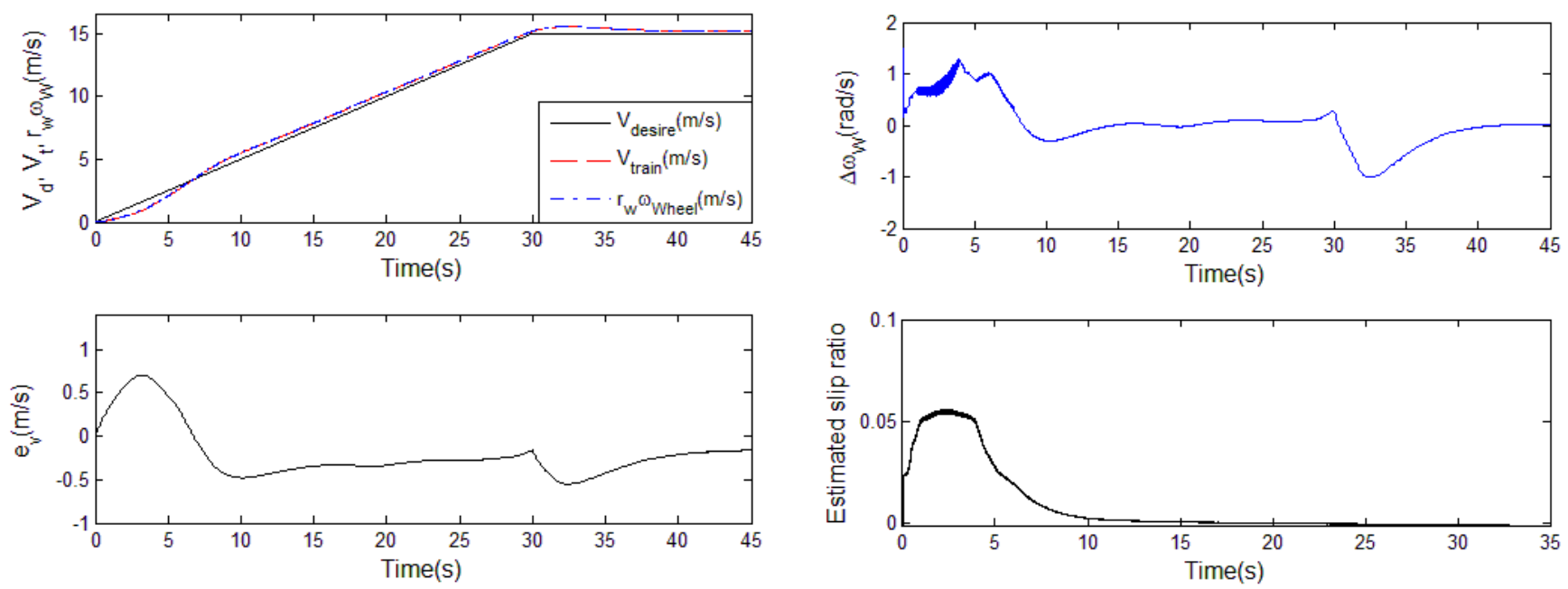

(a)

(b)

Fig. 10. Wet condition: (a) tracking the desired speed profile and error between the estimated longitudinal velocity and the desired speed profile; (b) $\Delta \omega_{w}$ and estimated slip ratio.
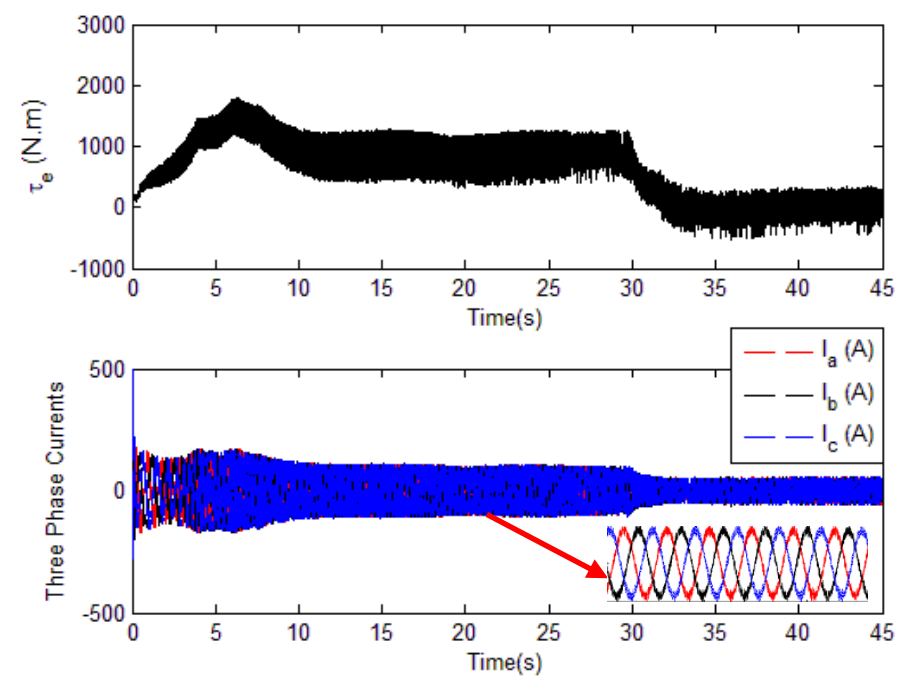

Fig. 11. Wet condition: electric torque and three phase currents.

\subsection{Case 3: Dry-wet condition}

In this case, the simulations have been performed for different rail and wheel surface conditions as shown in Table 4. At the onset of the motion, the condition of the rail and wheel is dry, and the desired acceleration of the train is $1 \mathrm{~m} / \mathrm{s}^{2}$. After 10 seconds, the wheel-rail surface condition changes to a wet surface, and the train tracks the corresponding desired speed profile while the desired acceleration changes to $0.5 \mathrm{~m} / \mathrm{s}^{2}$. Fig. 12. (a) shows that, during the acceleration, the desired slip ratio is obtained and maintained within the bounds $(0.035,0.05)$, and the longitudinal velocity of the train tracks the desired speed profile quite well. 
Table 4. Conditions of the wheel-rail surface over time.

\begin{tabular}{|c|c|}
\hline Time & Rail condition \\
\hline $0<t<10$ & Dry \\
\hline$t \geq 10$ & Wet \\
\hline
\end{tabular}
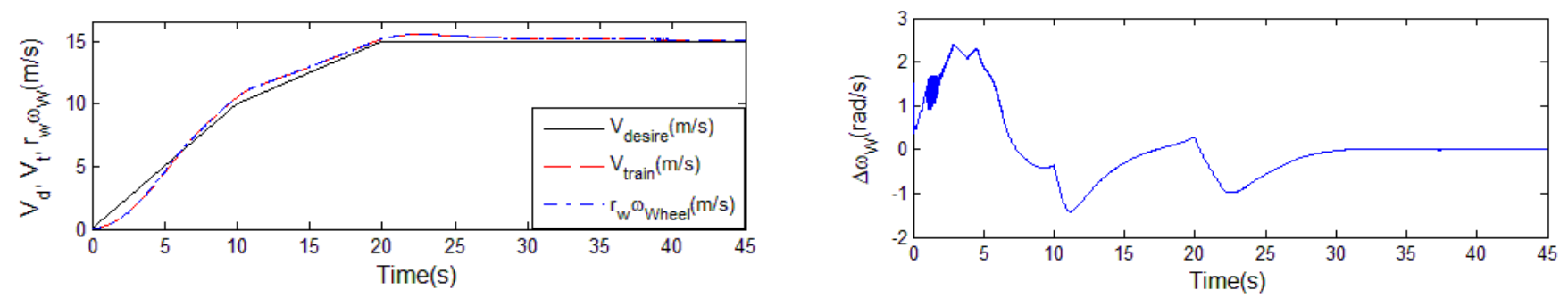

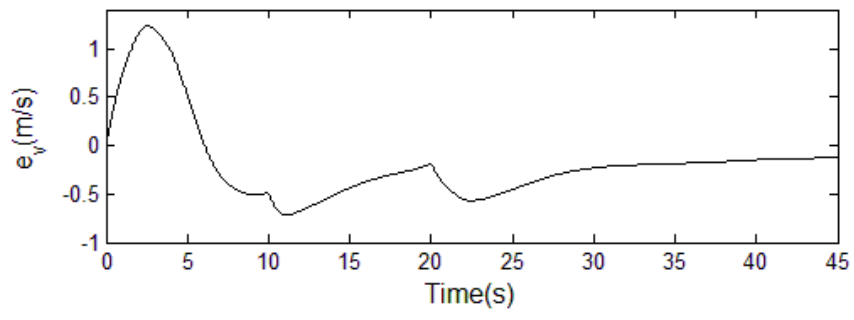

(a)

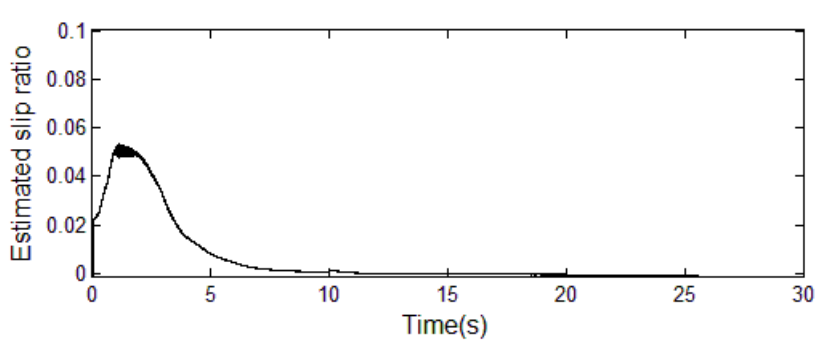

(b)

Fig. 12. Dry-wet condition: (a) tracking the desired speed profile and error between the estimated longitudinal velocity and the desired speed profile; (b) $\Delta \omega_{w}$ and estimated slip ratio.
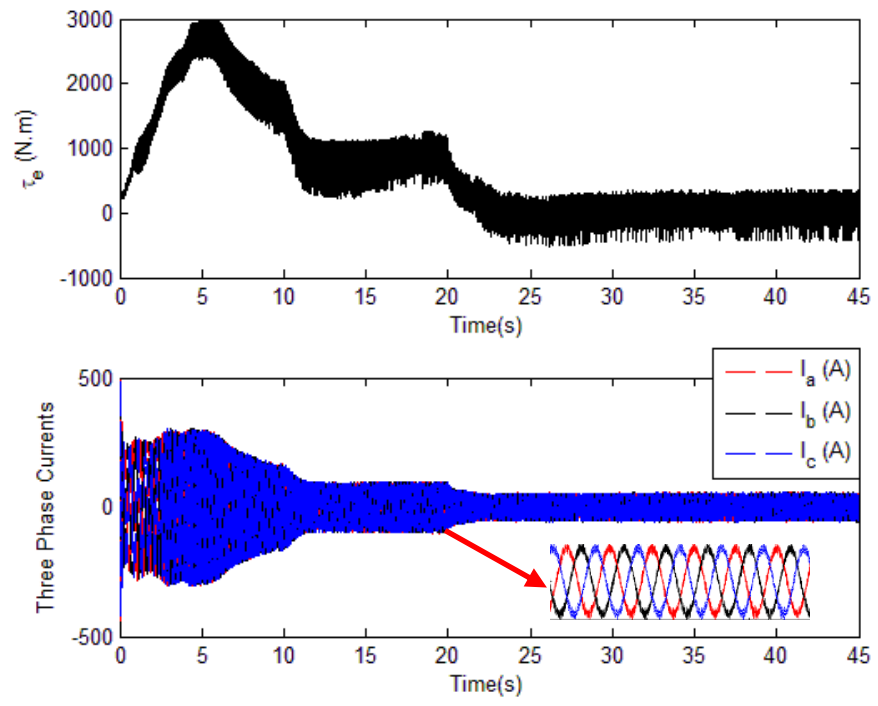

Fig. 13. Dry-wet condition: electric torque and three-phase currents.

\subsection{Estimator performance evaluation}

As previously mentioned, using a sensor-less approach, presented in Section 3.2; we have estimated the longitudinal velocity of the train and the slip ratio. To evaluate the accuracy 
of the proposed estimator, we have investigated the performance of it in the presence of the measurement noise. Since in a real condition, wheel speed, stator voltages and currents are measured along with noise. We assume that the measurement noise is a zero mean white Gaussian noise with 0.01 variance. Fig. 14, Fig.15, and Fig.16 present the estimated values in comparison with the actual value in dry, wet, and dry-wet conditions, respectively. Evidently, the simulation results show that the estimator has appropriate performance.
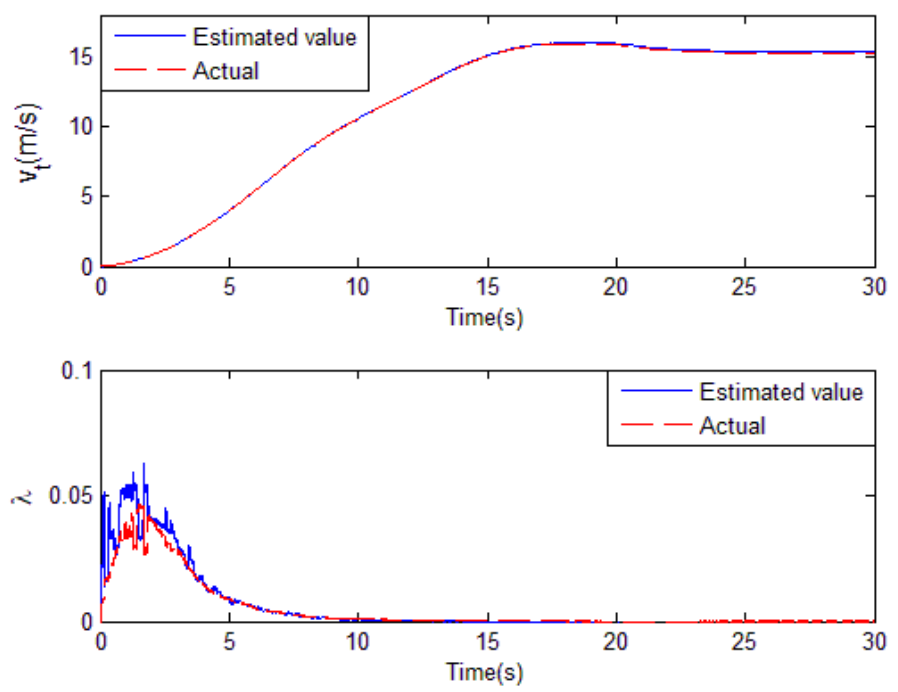

Fig. 14. Dry condition: Estimated value of longitudinal velocity in comparison with the actual value in the presence of measurement noise, and estimated value of slip ratio in comparison with the actual value in the presence of measurement noise.
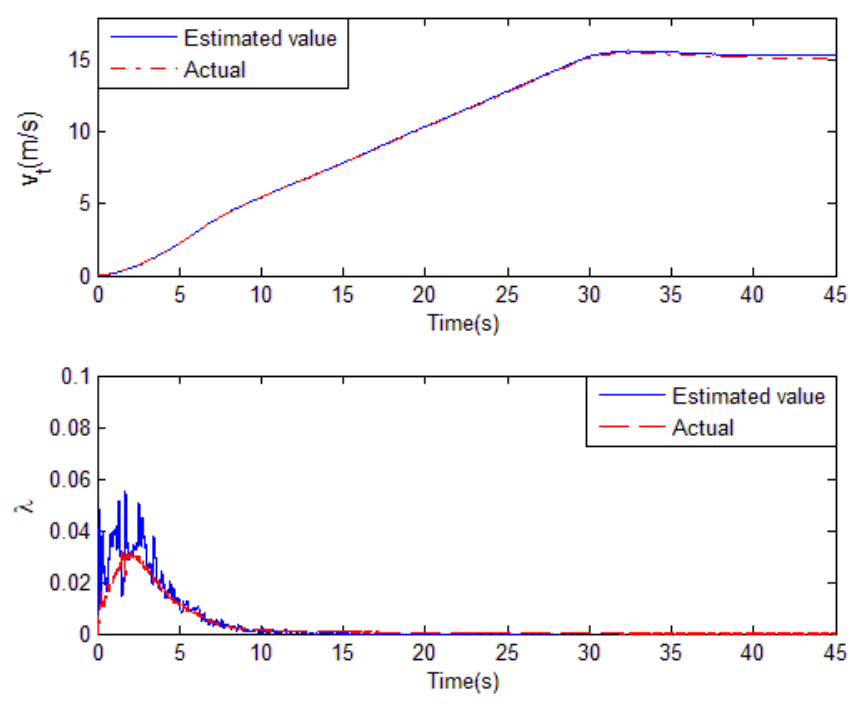

Fig. 15. Wet condition: Estimated value of longitudinal velocity in comparison with the actual value in the presence of measurement noise, and estimated value of slip ratio in comparison with the actual value in the presence of measurement noise. 

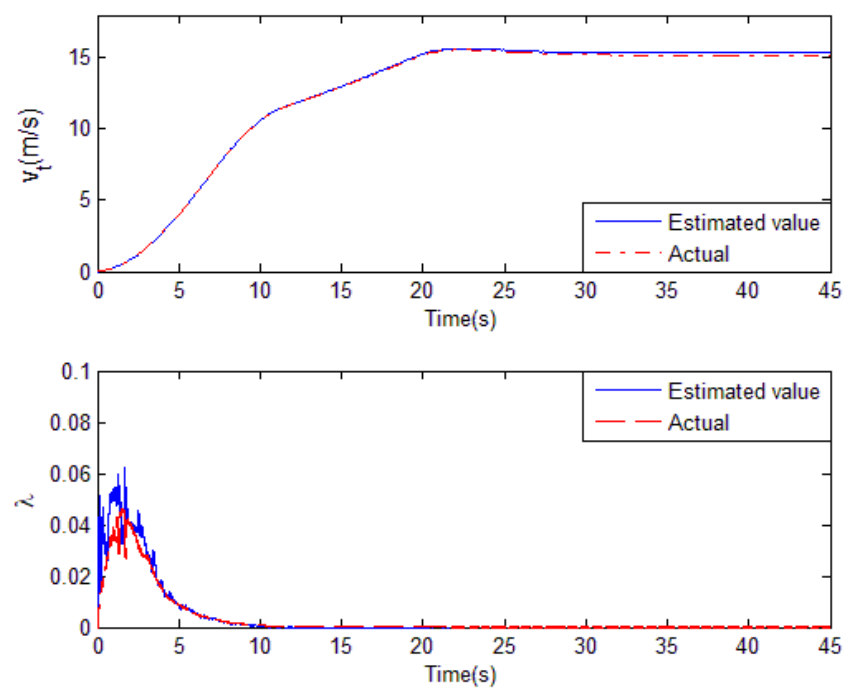

Fig. 16. Dry-wet condition: Estimated value of longitudinal velocity in comparison with the actual value in the presence of measurement noise, and estimated value of slip ratio in comparison with the actual value in the presence of measurement noise.

\section{Conclusion}

The current study introduced a fuzzy control system for tracking the desired speed profile in an electric train and simultaneously preventing the wheels from slipping. Fieldoriented control (FOC) was first designed to control the angular velocity of the motor; then a fuzzy controller was presented to generate an appropriate value of deviation for reference rotational speed. The simulation results show that the proposed scheme has effective performance in tracking the desired speed profile and provided the desired slip under different wheel-rail surface conditions. Furthermore, the simulation results demonstrate that the proposed algorithm has effective performance in different rail and wheel condition.

Further research can be done to improve the robustness of the proposed estimator in dealing with uncertainty in the parameters of locomotive and traction motors.

\section{References}

[1] X. Yang, X. Li, B. Ning, and T. Tang, "A survey on energy-efficient train operation for urban rail transit," IEEE Trans. Intell. Transp. Syst., vol. 17, no. 1, pp. 2-13, 2016.

[2] K. Kondo, "Anti-slip control technologies for the railway vehicle traction," 2012 IEEE Veh. Power Propuls. Conf. VPPC 2012, pp. 1306-1311, 2012.

[3] Ç. Uyulan and M. Gokasan, "Modeling, simulation and re-adhesion control of an induction motor-based railway electric traction system," Proc. Inst. Mech. Eng. Part I J. Syst. Control Eng., vol. 232, no. 1, pp. 3-11, 2018. 
[4] L. Fan, F. Cao, B. Ke, and T. Tang, "Speed profile optimization for train operation based on ant colony algorithm," in 2015 IEEE Advanced Information Technology, Electronic and Automation Control Conference (IAEAC), 2015, pp. 48-53.

[5] J. Yang, L. Jia, Y. Fu, and S. Lu, "Speed tracking based energy-efficient freight train control through multi-algorithms combination,” IEEE Intell. Transp. Syst. Mag., vol. 9, no. 2, pp. 76-90, 2017.

[6] B. Sarsembayev, T. Suleimenov, and M. Arpabekov, "Analyze of Impact of Track Alignment on the Energy Consumption Level,” Int. J. Traffic Transp. Eng., vol. 4, no. 2, pp. 45-59, 2015.

[7] H. Dong, B. Ning, B. Cai, and Z. Hou, "Automatic train control system development and simulation for high-speed railways," IEEE circuits Syst. Mag., vol. 10, no. 2, pp. 6-18, 2010.

[8] M. Chou and X. Xia, "Optimal cruise control of heavy-haul trains equipped with electronically controlled pneumatic brake systems," Control Eng. Pract., vol. 15, no. 5, pp. 511-519, 2007.

[9] Y. Ishikawa and A. Kawamura, "Maximum adhesive force control in super high speed train," in Power Conversion Conference-Nagaoka 1997., Proceedings of the, 1997, vol. 2, pp. 951-954.

[10] S. H. Park, J. S. Kim, and J. J. Choi, "Reference slip ratio generation and adaptive sliding mode control for railway rolling stocks," Int. J. Precis. Eng. Manuf., vol. 10, no. 2, pp. 39-44, 2009.

[11] W.-C. Cai, D.-Y. Li, and Y.-D. Song, "A Novel Approach for Active Adhesion Control of High-Speed Trains Under Antiskid Constraints,” IEEE Trans. Intell. Transp. Syst., vol. 16, no. 6, pp. 3213-3222, 2015.

[12] L. Li, S. Kodama, and Y. Hori, "Design Of Anti-Slip Controller For An Electric Vehicle With An Adhesion Status Analyzer Based On The Ev Simulator," Asian J. Control, vol. 8, no. 3, pp. 261-267, 2006.

[13] H. Yu, S. Taheri, J. Duan, and Z. Qi, “An integrated cooperative antilock braking control of regenerative and mechanical system for a hybrid electric vehicle based on intelligent tire," Asian J. Control, vol. 18, no. 1 , pp. 55-68, 2016.

[14] P. Píchlik and J. Zděnek, "Overview of slip sontrol methods used in locomotives," Trans. Electr. Eng., vol. 3, no. 2, pp. 38-43, 2014.

[15] T. Ishrat, G. Ledwich, M. Vilathgamuwa, and P. Borghesani, "Wheel slip control based on traction force estimaton of electric locomotives," in 2016 Australasian Universities Power Engineering Conference (AUPEC), 2016, pp. 1-6.

[16] H. Sun, Z. Hou, and T. Tang, "An Iterative Learning Approach for Train Trajectory Tracking Control 1," IFAC Proc. Vol., vol. 44, no. 1, pp. 14916-14921, 2011.

[17] D.-Y. Park, M.-S. Kim, D.-H. Hwang, J.-H. Lee, and Y.-J. Kim, "Hybrid re-adhesion control method for traction system of high-speed railway," in Electrical Machines and Systems, 2001. ICEMS 2001. Proceedings of the Fifth International Conference on, 2001, vol. 2, pp. 739-742.

[18] P. Pichlík and J. Zděnek, “Overview of slip control methods used in locomotives,” Trans. Electr. Eng., p. 38, 2014.

[19] K. Xu, G.-Q. Xu, and C.-H. Zheng, "Analysis of torque transmitting behavior and wheel slip prevention control during regenerative braking for high speed EMU trains," Acta Mech. Sin., vol. 32, no. 2, pp. 244$251,2016$.

[20] K. Xu, G. Xu, and C. Zheng, "Novel determination of Wheel-Rail adhesion stability for electric locomotives," Int. J. Precis. Eng. Manuf., vol. 16, no. 4, pp. 653-660, 2015.

[21] E. Nabizadeh, S. Javadi, and R. Sabbaghi-Nadooshan, "A Fuzzy Model for Slip Control in Rail Transportation Systems," Asin Trans. Fundam. Electron. Commun. Multimed., vol. 1, no. 3, pp. 7-12, 2011.

[22] S.-K. Kwon, U.-Y. Huh, H.-I. Kim, and J.-H. Kim, "Re-adhesion control with estimated adhesion force coefficient for wheeled robot using fuzzy logic," in Industrial Electronics Society, 2004. IECON 2004. 30th Annual Conference of IEEE, 2004, vol. 3, pp. 2530-2535. 
[23] M. Spiryagin, K. S. Lee, and H. H. Yoo, "Control system for maximum use of adhesive forces of a railway vehicle in a tractive mode," Mech. Syst. Signal Process., vol. 22, no. 3, pp. 709-720, 2008.

[24] D. Frylmark and S. Johnsson, “Automatic slip control for railway vehicles,” 2003.

[25] A. Mousavi, A. H. D. Markazi, and S. Masoudi, “Adaptive Fuzzy Sliding-Mode Control of Wheel Slide Protection Device for ER24PC Locomotive," Lat. Am. J. Solids Struct., vol. 14, no. 11, pp. 2019-2045, 2017.

[26] K. Lu, Y. Song, and W. Cai, "Robust adaptive re-adhesion control for high speed trains," 2014 17th IEEE Int. Conf. Intell. Transp. Syst. ITSC 2014, pp. 1215-1220, 2014.

[27] C. Uyulan, M. Gokasan, and S. Bogosyan, "Re-adhesion control strategy based on the optimal slip velocity seeking method," J. Mod. Transp., vol. 26, no. 1, pp. 36-48, 2018.

[28] L. Lu, W. Cai, and D. Li, "A Robust Adaptive Cooperative Control Method for Actuation Wheelsets of High-Speed Train,” in 2019 Chinese Control Conference (CCC), 2019, pp. 307-312.

[29] J. He, X. Zuo, C. Zhang, S. Mao, and Y. He, “Anti-slip control based on optimal slip ratio for heavy-haul locomotives,” J. Eng., vol. 2019, no. 23, pp. 9069-9074, 2019.

[30] K. Zhao, P. Li, C. Zhang, J. He, X. Li, and J. Liu, "Optimal Utilization of Adhesion Force for Heavy-Haul Electric Locomotive Based on Extremum Seeking with Sliding Mode and Asymmetric Barrier Lyapunov Function," J. Adv. Transp., vol. 2019, 2019.

[31] P. Pichlik and J. Zdenek, "Locomotive Wheel Slip Control Method Based on an Unscented Kalman Filter," IEEE Trans. Veh. Technol., vol. 67, no. 7, pp. 5730-5739, 2018.

[32] Y. Zhao and B. Liang, "Re-adhesion control for a railway single wheelset test rig based on the behaviour of the traction motor," Veh. Syst. Dyn., vol. 51, no. 8, pp. 1173-1185, 2013.

[33] S. Sadr, D. A. Khaburi, and J. Rodríguez, "Predictive Slip Control for Electrical Trains," IEEE Trans. Ind. Electron., vol. 63, no. 6, pp. 3446-3457, 2016.

[34] X. Wen, J. Huang, and S. Zhang, “Anti-Slip Re-Adhesion Control Strategy of Electric Locomotive Based on Distributed MPC," in 2019 IEEE 21 st International Conference on High Performance Computing and Communications; IEEE 17th International Conference on Smart City; IEEE 5th International Conference on Data Science and Systems (HPCC/SmartCity/DSS), 2019, pp. 2708-2713.

[35] T. X. Mei, J. H. Yu, and D. A. Wilson, "A mechatronic approach for anti-slip control in railway traction," IFAC Proc. Vol., vol. 41, no. 2, pp. 8275-8280, 2008.

[36] S. Kadowaki, K. Ohishi, T. Hata, N. Iida, M. Takagi, T. Sano, and S. Yasukawa, "Antislip readhesion control based on speed-sensorless vector control and disturbance observer for electric commuter trainSeries 205-5000 of the East Japan Railway Company," IEEE Trans. Ind. Electron., vol. 54, no. 4, pp. 2001-2008, 2007.

[37] A. Kawamura, T. Furuya, K. Takeuchi, Y. Takaoka, K. Yoshimoto, and M. Cao, "Maximum adhesion control for Shinkansen using the tractive force tester," in IECON 02 [Industrial Electronics Society, IEEE 2002 28th Annual Conference of the], 2002, vol. 1, pp. 567-572.

[38] T. Achour, M. Debbou, and M. Pietrzak-David, "Control strategy of a dual induction motor: Anti-slip control application,” Control Eng. Pract., vol. 36, pp. 58-71, 2015.

[39] L. Diao, L. Zhao, Z. Jin, L. Wang, and S. M. Sharkh, "Taking Traction Control to Task: High-AdhesionPoint Tracking Based on a Disturbance Observer in Railway Vehicles," IEEE Ind. Electron. Mag., vol. 11, no. 1, pp. 51-62, 2017.

[40] D. Angelosante, L. Fagiano, F. Grasso, and E. Ragaini, "Motor parameters estimation from industrial electrical measurements," in 2017 25th European Signal Processing Conference (EUSIPCO), 2017, pp. 1006-1010.

[41] F. Wang, Z. Zhang, X. Mei, J. Rodríguez, and R. Kennel, “Advanced control strategies of induction machine: Field oriented control, direct torque control and model predictive control," Energies, vol. 11, no. 1 , p. $120,2018$. 
[42] B. Moaveni, F. R. Fathabadi, and A. Molavi, "Supervisory predictive control for wheel slip prevention and tracking of desired speed profile in electric trains," ISA Trans., 2020.

[43] L. Zhou, W. Gruber, and D. L. Trumper, "Position control for hysteresis motors: Transient-time model and field-oriented control," IEEE Trans. Ind. Appl., vol. 54, no. 4, pp. 3197-3207, 2018.

[44] J. Zhang, H. Yang, T. Wang, L. Li, D. G. Dorrell, and D. D.-C. Lu, "Field-oriented control based on hysteresis band current controller for a permanent magnet synchronous motor driven by a direct matrix converter," IET Power Electron., vol. 11, no. 7, pp. 1277-1285, 2018.

[45] Z. A. Soomro, "Estimation of longitudinal velocity noise for rail wheelset adhesion and error level," Multiscale Multiphysics Mech., vol. 1, no. 3, pp. 261-270, 2016.

[46] J. Guzinski, H. Abu-Rub, M. Diguet, Z. Krzeminski, and A. Lewicki, "Speed and load torque observer application in high-speed train electric drive," IEEE Trans. Ind. Electron., vol. 57, no. 2, pp. 565-574, 2010.

[47] S. H. Park, J. S. Kim, J. J. Choi, and H.-O. Yamazaki, "Modeling and control of adhesion force in railway rolling stocks," IEEE Control Syst., vol. 28, no. 5, 2008.

[48] Piegat, Andrzej. Fuzzy modeling and control. Vol. 69. Physica, 2013. 
